\title{
DEMOCRATIZAR, DESCENTRALIZAR, MUNICIPALIZAR: A EXPANSÃO DO ENSINO FUNDAMENTAL CATARINENSE
}

\author{
IONE RIBEIRO VALLE \\ Centro de Ciências da Educação da Universidade do Estado de Santa Catarina \\ ionvalle@newsite.com.br \\ GLÁUCIA ELISA DE PAULA MIZUKI \\ Programa de Iniciação Científica do CNPq/Pibic para o Centro de Ciências \\ da Educação da Universidade do Estado de Santa Catarina \\ glauciamizuki@ibest.com.br \\ INAIARA MARIA FERREIRA DE CASTRO \\ Programa de Iniciação Científica do CNPq/Pibic para o Centro de Ciências \\ da Educação da Universidade do Estado de Santa Catarina \\ inaiaracastro@terra.com.br
}

\section{RESUMO}

\begin{abstract}
Este estudo analisa a dinâmica sobre a qual repousa a municipalização do ensino, após os anos 1980. Procuramos, inicialmente, retraçar as grandes linhas das políticas de educação que preconizam a democratização, tendo por referência a situação dos municípios do Estado de Santa Catarina na ampliação das oportunidades educacionais. Construímos, em seguida, um esquema de interpretação sociológica, colocando em evidência algumas lógicas subjacentes a essas políticas educacionais, a saber: uma lógica segregativa, relacionada aos processos pedagógicos de caráter excludente; uma lógica integradora, que faz referência ao princípio meritocrático procurando explicar as posições dos indivíduos nos diversos grupos sociais; uma lógica descentralizadora, que tem por objetivo reorientar o poder decisório predominante no interior dos sistemas de ensino; uma lógica municipalista, associada à democratização e à repartição das responsabilidades em termos de escolarização fundamental.
\end{abstract}

DEMOCRATIZAÇÃO DAEDUCAÇÃO-EDUCAÇÃO-ENSINO FUNDAMENTAL - SANTA CATARINA

\section{ABSTRACT}

DEMOCRATIZING, DESCENTRALIZING, MUNICIPALIZING: ELEMENTARYEDUCATION EXPANSION IN SANTA CATARINA. This study analyses the dynamics of the municipalization of education after the 80 's. Firstly, we sought to draw the lines of educational policies that recommend democratization, by focusing on the conditions to expand educational opportunities in some 
municipalities in the State of Santa Catarina. Next, we developed a schematic drawing for sociological interpretation, highlighting some underlying logic in these educational policies, such as: the segregationist logic related to excluding pedagogical processes; the integrator logic that refers to the merit principle, which tries to explain the positions of individuals in different social groups; the decentralizing logic aiming at redirecting the dominant decision making power in educational systems; the municipalist logic associated to democratization and to the sharing of responsibilities regarding elementary schooling.

DEMOCRATIZATIONOFEDUCATION_EDUCATION_FUNDAMENTAL TEACHINGSANTACATARINA

A democratização do ensino, entendida muito mais como ampliação das oportunidades de escolarização do que como instituição de procedimentos e implantação de práticas que permitam a participação de todos nas deliberações de um corpo coletivo (nos termos propostos por Bobbio, 1990), integra os princípios que motivaram a constituição de um sistema de educação nacional. A intenção de escolarizar a população brasileira e, mais recentemente, de estender seus níveis de escolaridade esteve sempre relacionada à idéia - que goza de amplo consenso - de que a educação é indispensável à concretização do projeto de desenvolvimento, seja ele de base nacional ou orientado por organismos internacionais (Nações Unidas, Banco Mundial, Organização dos Estados Americanos, Fundo Monetário Internacional, por exemplo).

A tradição federalista', que definiu os contornos políticos da nação brasileira e norteou as reformas educacionais anteriores à Lei de Diretrizes e Bases da Educação Nacional ${ }^{2}$, introduziu também os fundamentos do sistema educacional em vigor. Ora, essa tradição abriga incompatibilidades importantes, como mostra Cury (2000, p.570) referindo-se ao fato de que o direito à educação ainda não está

I O federalismo brasileiro passou por diferentes etapas, coincidentes com as reformas constitucionais, embora o regime tenha sido implantado apenas em I89| com a promulgação da Primeira Constituição Republicana, gostaríamos de reter aqui alguns indicadores que remontam ao período colonial. Segundo Cruz (1987, p.469-47I), "os atuais estados-membros são [na sua maioria] os sucessores das províncias imperiais e estas, das capitanias hereditárias [as quais permaneceram como as bases políticas, culturais, sociais e econômicas das ordens subseqüentes] instituídas por D. João III para colonizar, por meio de uma administração descentralizada, o imenso território sob seu domínio".

2 A primeira LDB (196I) foi precedida pelas seguintes reformas educacionais: Leôncio de Carvalho (I879), Benjamin Constant (1890), Epitácio Pessoa (I90 I), Rivadávia Corrêa (191 I), Maximiliano (1915), Rocha Vaz (1925), João Luis Alves (1925), Francisco Campos (1931) e Capanema (1942). 
consolidado como um direito social, pois "os direitos civis e políticos proclamados se mesclaram com uma prática de discriminação e de privilégio".

Os princípios de uma democracia liberal ${ }^{3}$, inspirada no ideal republicano ${ }^{4}$, fundamentaram as primeiras promessas de democratização do ensino, associandoas à noção de descentralização ${ }^{5}$. É esta noção que vai primeiramente impulsionar a constituição dos sistemas estaduais e, em seguida, justificar a necessidade de estruturação dos sistemas municipais de ensino ${ }^{6}$.

Amado (1973, p. 102-109) mostra que, além de estar no centro dos debates ou das disputas que marcaram a aprovação da primeira Lei de Diretrizes e Bases, a estrutura do sistema de ensino brasileiro tem origem em duas tendências opostas. De um lado, encontravam-se os centralizadores, que preferiam "minudenciar, se não esgotar na lei, os preceitos de conteúdo administrativo e didático, ficando circunscrita à iniciativa dos poderes locais a simples criação e distribuição de escolas, copiadas estas de padrões prefixados pela União". A descentralização defendida por esta tendência tinha como sentido a "transferência de poderes da administração pública para os órgãos de direção do sistema educacional". Do outro lado, estavam os autonomistas extremados, que "pleiteavam uma lei de muito poucos artigos, todos sintéticos e amplos, deixando às unidades federadas (e até mesmo aos particulares) uma liberdade quase total". Estes queriam assegurar "amplos poderes aos sistemas locais e, dentro deles, alguma liberdade de movimentos às escolas". Para Amado, o que prevaleceu nessa lei foi uma harmonia entre as duas tendências:

princípio de descentralização não se manteve em termos tão absolutos como desejavam os seus pertinazes apologistas; não tão utópicos, e sim em termos mais

3 Concepção ambígua que, para Macpherson (1978, p.9), significa ao mesmo tempo a "liberdade do mais forte para derrubar o mais fraco de acordo com as regras do mercado" (lógica capitalista) e a garantia de liberdade para que todos possam empregar e desenvolver suas capacidades.

4 Embora reconheçamos que os princípios da democracia liberal estejam muito próximos do ideal republicano, consideramos importante ressaltar, a exemplo de alguns autores, que há uma certa distinção entre eles. Enquanto a noção de república está marcada pelo universalismo abstrato e laico, a concepção de democracia liberal parece mais atenta às identidades comunitárias e às minorias.

5 Segundo Tocqueville (| 803- | 859), a tradição centralizadora precede a Revolução Francesa e data do antigo regime, prevalecendo nos regimes que se diziam democráticos.

6 Sobre a evolução histórica da descentralização do ensino, no que concerne particularmente à sua "vertente municipalizadora", ver estudo de Oliveira (1999, p. I l-36). 
realistas de equilíbrio entre a autonomia dos sistemas locais e a presença coordenadora ou, mesmo, o controle do poder central. (1973, p. I06)

Mas seriam as lutas por democratização geral da sociedade, que irrompem sobretudo a partir de 1980, conduzindo a mudanças estruturais e legais importantes (como a queda do regime ditatorial em 1985, a promulgação da Constituição Federal de 1988 e a aprovação da nova Lei de Diretrizes e Bases da Educação Nacional em 1996), que iriam dar maior amplitude ao discurso descentralizante. As medidas de descentralização passam a figurar entre os principais objetivos das esferas administrativas (federais e estaduais) ligadas à educação nacional e implicam, fundamentalmente, a criação e/ou expansão das redes municipais, gerando o movimento denominado municipalização do ensino ${ }^{7}$.

Para as redes municipais convergem praticamente todas as expectativas concernentes à ampliação das oportunidades de acesso e permanência no ensino fundamental, obrigatório desde a promulgação da reforma de 1971. A municipalização passa a ser vista como a solução privilegiada para os males endêmicos que afetam a educação nacional. Pensar em termos de rede municipal é pensar em integração, socialização, participação, escolarização compartilhada pela comunidade. Aproximando a escola dos agentes e daqueles que têm o poder de decisão local, propaga-se igualização das condições de acesso à instrução escolar, maior transparência na gestão e aplicação mais racional dos recursos destinados à educação. Anuncia-se assim que descentralização rima com democratização.

É nesse quadro de múltiplas expectativas, em que se combinam interesses heterogêneos, muitas vezes opostos, que inscrevemos este estudo, cujo objetivo principal consiste em analisar a contribuição das redes municipais de ensino ao processo de democratização da educação no Estado de Santa Catarina, a partir de dados estatísticos recolhidos em fontes secundárias (Valle, Mizuki, Castro, 2003).

Partimos da constatação de que o sistema de ensino apresenta-se estratificado em redes e níveis, favorecendo a reprodução de desigualdades profundas que operam em favor da segregação social e escolar. Tendo sido separadas desde o início em seus percursos escolares, as crianças brasileiras têm suas condições de origem reforçadas por uma estrutura organizacional - igualitária nos seus princípios

7 Em outubro de 1986, foi criada a União Nacional dos Dirigentes Municipais de Educação Undime -, entidade composta pelos secretários municipais de educação com a finalidade de ampliar o espaço de participação política dos municípios brasileiros. 
constitutivos mas fortemente diferenciada nas suas práticas - que acaba orientando, se não determinando, suas escolhas profissionais e perpetuando sua posição na classe social.

Por outro lado, não podemos desconsiderar o fato de que a descentralização favorece a emergência de novos atores sociais e a afirmação de outros poderes, sendo um instrumento potencialmente favorável às mudanças e às discussões políticas e educacionais, que se devem travar nas coletividades locais. Ainda, não há como negligenciar a participação dos sistemas municipais na ampliação das oportunidades de escolarização: a municipalização tornou efetiva a abertura da escola a crianças de todas as origens sociais.

Considerando a dinâmica profundamente contraditória que caracteriza a municipalização do ensino em Santa Catarina, formulamos a hipótese segundo a qual as esferas federais e estaduais investem na descentralização não somente porque estão engajadas na democratização da educação e desejam repartir as responsabilidades educacionais a fim de melhor concretizá-la, mas também porque querem reduzir os investimentos em matéria de educação e pôr termo a um sistema centralizado, que não corresponde mais às expectativas sociais e às especificidades de um Estado federado.

Para examinar nossa hipótese principal, elaboramos duas questões centrais que possibilitarão apreender essa dinâmica e orientar nosso estudo: I . a ampliação das oportunidades de escolarização, que indiscutivelmente preserva um caráter democrático, não parece estar associada à redução das disparidades escolares; 2. a municipalização pode ser vista como a entrada na segunda "onda" da massificação do ensino fundamental catarinense, entendendo que a primeira "onda" foi deflagrada em 1970 sob a chancela dos governos estaduais.

A fim de examinar a dinâmica sobre a qual repousa a municipalização do ensino, procuramos primeiramente retraçar as grandes linhas das políticas de educação que preconizam a democratização, tendo por referência a participação dos municípios do Estado de Santa Catarina na ampliação das oportunidades educacionais. Visando alcançar maior objetividade na análise do corpus de informações, construímos, num segundo momento, um esquema de interpretação sociológica, colocando em evidência algumas lógicas subjacentes a essas políticas educacionais, a saber: uma lógica segregativa, relacionada aos processos pedagógicos de caráter excludente; uma lógica integradora, que faz referência ao princípio meritocrático, procurando explicar as posições dos indivíduos nos diversos grupos sociais; uma lógica descentralizadora, que tem por objetivo reorientar o poder decisório predominante no inte- 
rior dos sistemas de ensino; uma lógica municipalista, associada à democratização e à repartição das responsabilidades em termos de escolarização fundamental.

\section{O PESO DAS POLÍTICAS EDUCACIONAIS}

Em tempos de insegurança e de incertezas, é a estabilidade que é solicitada. Em períodos mais conturbados, é aos princípios democráticos que se faz apelo. Em épocas mais estáveis e, portanto, mais favoráveis à concretização de velhos sonhos, os direitos ${ }^{8}$ civis é que são evocados. Em momentos de conquistas favoráveis aos novos projetos, é a necessidade de educação que é principalmente ressentida e para a qual se exortam os sistemas de ensino a mudar. Em conseqüência disso, consideramos que toda a análise deverá focalizar - ainda que brevemente - a dinâmica dos diferentes contextos históricos.

A conjuntura político-econômica brasileira da segunda metade dos anos 70 (século $X X$ ) apresentava-se por demais tumultuada, forçando o regime militar a introduzir novas estratégias político-administrativas, que visavam à legitimação do poder autoritário. O governo enfrentava, de um lado, a resistência de seus adversários cada vez mais organizados e mobilizados; de outro, confrontava-se com o descontentamento crescente de uma parte da burguesia que o apoiara, cujos interesses não vinham sendo contemplados a contento. Além disso, sua hegemonia fora fortemente atingida pelo fracasso dos planos e ações governamentais, fato que alimentou as críticas relativas ao projeto de desenvolvimento econômico implantado e ao modelo de gestão política em vigência, os quais não correspondiam às aspirações mínimas da sociedade. Evidentemente, essa situação conferia dinamismo às perspectivas de mudança pretendidas pelos opositores do regime.

As demandas exprimidas pelos movimentos sociais desde o início do século, que haviam sido reafirmadas com vigor nos anos 50 e 60, ressurgiam com muito mais intensidade, pois a condição de desigualdade profunda (social, econômica, política, cultural, educacional) continuava a afetar a maioria da população. Apesar do endurecimento dos mecanismos de repressão observado nos últimos anos, os sinais de crise do regime autoritário eram flagrantes. A recessão econômica estimulou, nos mais diversos setores da sociedade, uma seqüência de tensões, as quais

8 Direitos que, segundo Lefort (1983, p.57), não se dissociam da "consciência dos direitos [que] se encontra tanto melhor partilhada quando [os direitos] são declarados, quando o poder afirma garanti-los, quando as marcas das liberdades se tornam visíveis pelas leis". 
provocaram uma simulação de abertura do regime sob a presidência de Geisel (1974-1979). Mas foi durante o Governo Figueiredo (1979-1985) - um governo que oscilava entre abertura e repressão - que as medidas autoritárias apresentaram maior fragilidade, favorecendo a emergência de novas forças democráticas e a efervescência de movimentos sociais, sufocados durante algumas décadas.

A situação em que se encontravam os sistemas de ensino explicitava claramente a contradição entre o discurso e a prática do regime autoritário. A escolarização permanecia inacessível à maioria das crianças e jovens brasileiros, seus percursos escolares marcados pelo fracasso escolar denunciavam o caráter elitista da educação nacional. Embora as instâncias oficiais de Santa Catarina tenham considerado positivo o crescimento da matrícula, verificamos que a obrigatoriedade do ensino fundamental continuava longe de ser cumprida, como ilustram alguns dados levantados em documentos oficiais:

- a taxa dos alunos escolarizados de I a $4^{\mathrm{a}}$ série evoluiu de $60 \%$ para $71 \%$ no período compreendido entre 1970 e 1978. Quase 30\% das crianças continuavam fora da escola;

- a taxa dos alunos escolarizados de la a 8a série não ultrapassou os 32\% no mesmo período. Quase 70\% das crianças em idade escolar eram afetadas pelo fracasso escolar;

- o ponto crítico deste nível de ensino estava situado na passagem da 4a para a $5^{a}$ série. Entre os alunos matriculados na $4^{a}$ série (no período de 1975 e 1978), somente $42 \%$ prosseguiram seus estudos. As dificuldades para ultrapassar a barreira de acesso à $5^{a}$ série atingiam sobretudo as crianças da zona rural, que residiam longe das escolas de $5^{\mathrm{a}}$ a $8^{\mathrm{a}}$ série e não tinham acesso a nenhum meio de locomoção;

- a taxa de abandono anual dos alunos de I a a $8^{a}$ série atingiu 56\% em 1970 , tendo baixado para 42\% em 1977. Quase metade das crianças era expulsa da escola antes de concluir o nível de escolarização obrigatória. (Santa Catarina, 1969)

Além do atraso educacional ${ }^{9}$, confirmado pelos próprios indicadores oficiais, à escola era atribuída uma parte importante da responsabilidade pela perpetuação

9 Ou baixa produtividade do sistema, segundo a expressão empregada nos documentos oficiais. 
das estruturas de dominação. Algumas pesquisas em educação utilizavam a noção de "reprodução" para caracterizar a situação da educação brasileira. Inspiravam-se em estudos elaborados principalmente na França por Bourdieu e Passeron (1964) que se empenharam em desvelar a função reprodutora preenchida de maneira implacável pela escola. Esses estudos encorajaram uma atitude crítica diante dos sistemas de ensino e influenciaram significativamente o chamado pessimismo pedagógico, em oposição ao otimismo pedagógico, veiculado pelas políticas oficiais e fundamentado no discurso escolanovista, que alimentou as retóricas político-pedagógicas ao longo do século $X X$. Eles alertaram também para o papel que desempenhava a escola na "naturalização" das desigualdades escolares e na dissimulação dos antagonismos entre classes sociais.

Em uma outra perspectiva, Arroyo (1989) assinala que, apesar de se verificar um aumento dos índices de escolarização, as taxas de analfabetismo continuavam muito altas ${ }^{10}$. Além disso, a educação das crianças das classes menos favorecidas permanecia centralizada na aquisição de uma formação rudimentar que facilitava sua rápida inserção no mercado de trabalho. Projetos educacionais mais amplos, levando em consideração o direito a desenvolver o espírito crítico e o raciocínio pela comunicação oral e escrita, eram negligenciados para a maioria dessas crianças.

A titulação do corpo docente aparece como uma das causas principais do baixo rendimento dos sistemas de ensino, sendo reconhecida tanto pelas esferas administrativas quanto pelas esferas representativas do pessoal da educação (associações e sindicatos). Como mostram Valle, Mizuki e Castro (2003), o nível de formação dos professores catarinenses de $1^{\mathrm{a}}$ a $8^{\mathrm{a}}$ série em 1978 era inferior às exigências legais: o melhor desempenho era da rede estadual (responsável por 75\% do contingente), em que $43 \%$ dos professores tinham ao menos uma formação secundária específica para o exercício da profissão, contra 30\% da rede municipal (responsável por 19\% da matrícula). A rede privada (que mantinha 6\% da matrícula) possuía apenas $26 \%$ de seus professores habilitados.

Apesar das críticas dirigidas à política de educação nacional, a entrada nos anos 80 é caracterizada pelo forte engajamento da sociedade civil na luta para assegurar a todos o direito "sagrado" à educação. Contudo, se examinarmos a pirâmide de escolarização fundamental e média (Gráf. I), verificamos que a população de

10 Em Santa Catarina, por exemplo, a população analfabeta era de $18 \%$ em 1980 e de $13 \%$ em 199| (cf. Recenseamentos de 1980 e 199|). 
GRÁFICO I

PERCENTUAL DE ALUNOS MATRICULADOS NO ENSINO FUNDAMENTAL E MÉDIO, POR SÉRIE E NÚMERO DE CONCLUINTES DO ENSINO MÉDIO SANTA CATARINA, 1989-1999

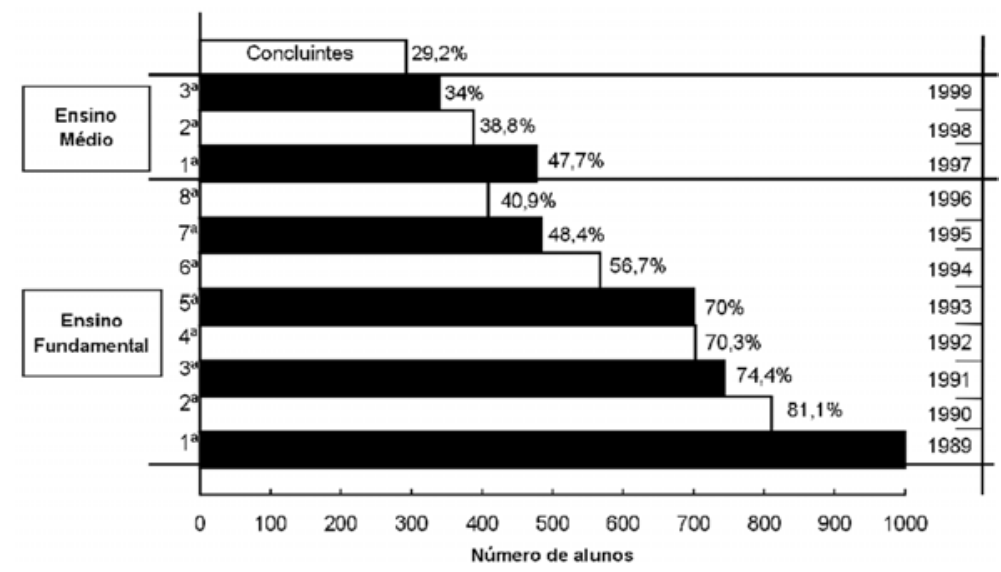

Fonte: Santa Catarina, Secretaria de Estado da Educação e do Desporto, 1989-1999 e 1980-2000.

Santa Catarina, por exemplo, chega ao fim do milênio sem se beneficiar de um sistema de ensino verdadeiramente democrático: de cada mil crianças que ingressam na la série em 1989, apenas 41\% estão matriculadas na $8^{a}$ série em 1996; menos de 30\% delas concluem o ensino médio em 1999. Estes indicadores revelam que o déficit de escolarização e o fracasso escolar, fortemente combatidos ao menos desde os anos 70, resistem às medidas administrativas, assumem outras formas no cotidiano da escola e desafiam as forças sociais envolvidas na democratização da educação.

\section{AMBIGÜIDADES DA DEMOCRATIZAÇÃO DA EDUCAÇÃO}

\section{Uma lógica segregativa: porta aberta à exclusão escolar}

Para compreender os avanços provocados pelas políticas públicas, sobretudo os seus limites, pesquisadores de diversas áreas reintroduzem alguns conceitos 
clássicos como os de pobreza e de precariedade, por exemplo, atribuindo-lhes nova interpretação. $\bigcirc$ objetivo é fugir das definições estáticas, que ocultam as lógicas segregativas, e construir categorias que permitam analisar a realidade social e educacional de maneira dinâmica e multidimensional. A noção de exclusão permite ampliar esses conceitos e se revela uma das mais frutíferas, pois demonstra que não se pode explicar a condição de precariedade das populações desfavorecidas apenas em termos de oposição entre interesses classistas. Essa condição é sobretudo decorrente de sua fragilidade diante dos mecanismos de discriminação e de reprodução social, cuja finalidade é desarticular e desmobilizar, criando assim obstáculos às reivindicações das populações desfavorecidas e freando a emergência de movimentos suscetíveis de reforçar uma coesão identitária.

Segundo Castel (1996), a exclusão não pode ser definida unicamente como uma não-integração no trabalho, na escola ou em outras instituições sociais; ela é também uma não-inserção na sociabilidade sociofamiliar, uma désaffiliation; isto é, uma dissociação dos vínculos sociais. Para Dubet (1996), é necessário considerar que a exclusão concerne um processo de degradação das relações sociais, estando presente no centro dos espaços sociais mais marginalizados, os quais, na maioria das vezes, se apresentam bem circunscritos geograficamente, constituindo a chamada "segregação espacial" (Zanten, 1996, p.282). Não se trata simplesmente de designar um ou vários grupos sociais marcados por uma exclusão escolar de fato, mas sobretudo de pôr em relevo a existência de processos sociais que, ao menos implicitamente, conduzem a essas situações extremas.

Visando orientar e fundamentar nosso estudo referente à municipalização do ensino, procuramos analisar a exclusão no âmbito da escola, nos inspirando em trabalhos de alguns pesquisadores em educação que, a partir de diferentes contextos educacionais, procuraram decifrar os mecanismos de segregação empregados no interior da escola. Segundo Zanten (1996, p. 28I), é necessário estudar a fabricação da segregação; isto é, os processos que intencionalmente marginalizam, resultantes das práticas individuais discriminatórias ou das ações internas ou externas às instituições educacionais, organizadas principalmente pelo Estado. Mas é necessário também analisar a segregação no espaço escolar como um processo que, a um dado momento, pode produzir efeitos específicos sobre a atuação dos estabelecimentos de ensino ou sobre o funcionamento do contexto local e da sociedade global.

A exclusão pode advir das lógicas segregativas, segundo Dubet(1996, p. 497). Desta maneira, ela visa às minorias étnicas, mas pode ser também institucional e aparecer como uma conseqüência própria do funcionamento das instituições. É neste 
último caso que o autor situa a escola que, sem correr o risco de exagerar, marcha para uma "exclusão relativa" (na qual o aluno escolhe somente aquilo que lhe resta escolher em razão de seu desempenho). Multiplicando os critérios de seleção e tornando cada vez mais complexa a estrutura organizacional, a educação escolar não parece voltada para a igualdade de chances e a mobilidade social como predizem seus princípios norteadores: a escola simplesmente oferece novas oportunidades para os melhores.

Para Ferraro (1999), a exclusão escolar brasileira apresenta dupla face. Ela compreende tanto o não-acesso à escola - exclusão da escola - (fenômeno que se mantém importante, atingindo em 200 I quase 4\% da infância brasileira em idade escolar obrigatória' ') quanto o abandono da escola - exclusão na escola - (fenômeno que denuncia a baixa qualidade da educação nacional: de cada 100 alunos que ingressam no ensino fundamental em 200 I, apenas 59 o concluem; 39\% dos que o freqüentam estão com idade superior à série em conseqüência das altas taxas de repetência, que permanecem em torno de $22 \%^{12}$ ). Para o autor, a exclusão na escola é provocada pelos mecanismos que fabricam o fracasso escolar. Ele lembra que a escolarização ainda é uma tarefa inacabada e muito complexa: "Não se trata simplesmente de caçar os fujões ou de puxar as orelhas dos preguiçosos".

Ainda, corroborando esta mesma perspectiva de análise crítica dos sistemas de ensino, destacamos o estudo de Zago (2000), elaborado em Santa Catarina, o qual afirma que há uma grande distância entre as intenções das políticas de democratização da educação e a realidade escolar das camadas sociais menos favorecidas. A escola brasileira apresenta altas taxas de abandono que são a expressão de um ensino elitista e excludente. Certamente houve um aumento importante das oportunidades de escolarização, porém ele não foi seguido de melhor qualidade, capaz de produzir mais igualdade escolar: se a população menos favorecida beneficia-se da extensão do ensino obrigatório, ela não se beneficia em condições de igualdade.

\section{Uma lógica integradora: o mito meritocrático}

Como se pôde ver, o projeto democrático construído durante décadas continua no centro das discussões educacionais, concebendo a escola como instituiçã̃o

I I Dados obtidos junto ao Censo do Inep/MEC, aplicado em 200 I e publicado em março de 2003.

12 Idem. 
de socialização e como aparelho de integração social. Segundo Dubet (1996, p. 498), mesmo as teorias da reprodução reafirmam esta lógica integradora ao considerarem que "a escola dá a cada um o lugar que lhe é destinado". É a igualdade de chances que elas colocam em dúvida e não a integração ou a exclusão dos indivíduos.

Mas as lutas por democratização da educação, que em diferentes momentos históricos se confundem com a idéia de integração nacional, conservam contradições profundas: uns estão empenhados na manutenção de uma ordem institucional, que atribui à democracia um sentido estritamente econômico, e imaginam a escola como via privilegiada para a concretização de seus objetivos (principalmente no que concerne à qualificação de mão-de-obra); outros defendem a busca de soluções para as desigualdades escolares que cindem a infância e a adolescência brasileira.

Se estimarmos que esse projeto está calcado em princípios que buscam dissociar ao máximo o sucesso escolar da origem social dos alunos, então a democratização da educação não teve êxito. As medidas sucessivas visando à universalização do ensino fundamental não parecem destinadas a oferecer a todos as mesmas oportunidades de sucesso escolar. Estimulando os dons, a vocação e os méritos individuais, mas imputando também o fracasso escolar à influência de certos condicionantes socioeconômicos, reconhece-se como inevitáveis - ou provavelmente como legítimos - o enquadramento, a classificação, a seleção, a exclusão; o que demonstra que a insensibilidade a todo tipo de desigualdade não perdeu sua força.

Nas sociedades qualificadas como democráticas é o princípio meritocrático que alicerça as posições ocupadas pelos indivíduos nos diferentes grupos sociais. Posições que gozam de maior prestígio e reconhecimento são justificadas pela lógica meritocrática, a qual ratifica tanto o sucesso quanto o fracasso escolar. Isto nos leva a considerar, como o fizeram Bourdieu e Passeron (1964), que, concretizando a igualdade formal de chances, a escola pode colocar todas as aparências da legitimidade a serviço da legitimação dos privilégios.

Mas essa lógica não é tão consensual como parece à primeira vista. Definindo as expectativas educacionais somente em termos de produtividade econômica e de mobilidade social, ela acaba contrapondo-se à dinâmica de funcionamento da sociedade. É evidente que a escola se mostra incapaz de promover a igualdade de oportunidades e de garantir uma seleção justa, pois as chances dos indivíduos não são idênticas desde que ingressam na escola; também não são similares os níveis de conhecimento e as condições pedagógicas oferecidas pelas diferentes redes de ensino.

Nossos sistemas educacionais estão, portanto, longe de proporcionar uma eqüidade de acesso à escola, associada a recursos pedagógicos de igual qualidade 
que permitam suprimir as desigualdades iniciais, "colocando os ponteiros no zero", e tornem possível a expressão das diferenças individuais em toda a sua plenitude. $\mathrm{Na}$ verdade, embora as desigualdades diante da escola tenham se tornado menos visíveis, não significa que desapareceram, nem mesmo perderam em dimensão. Sua persistência está enraizada em outras desigualdades fundamentais, progressivamente incorporadas sob a forma propriamente escolar. Além disso, a escola acaba favorecendo a multiplicação das desigualdades e a criação de outras: os alunos progridem mais ou menos segundo a rede de ensino, o estabelecimento escolar, o turno e até mesmo a classe freqüentada.

A promessa de igualdade, ancorada na massificação e na eficiência da escola, opõe-se à lógica das sociedades marcadas pelas desigualdades. As conseqüências sobre a inserção socioprofissional são profundas: nesta são computados outros capitais (econômico, cultural, social) normalmente não disponibilizados aos jovens de classes desfavorecidas, como mostram os estudos efetuados por Langouët (2002, p.85-105).

Embora reconheçamos que maior eficiência possa beneficiar as crianças pedagogicamente mais frágeis e diminuir sua distância em relação aos portadores da cultura escolar e social legítima (os "herdeiros", segundo Bourdieu, 1979), não podemos ignorar que geralmente essas crianças freqüentam os estabelecimentos menos eficientes, têm os professores mais jovens ${ }^{13}$ menos habilitados e menos experientes: 50\% dos professores da educação básica catarinense tinham em média 35 anos em 1997; a média de idade dos professores aumenta à proporção que se eleva o nível de ensino; 40\% dos professores catarinenses, atuando na rede estadual, são diplomados no ensino superior contra $22 \%$ das redes municipais; mais de dois terços dos professores das redes municipais têm somente o nível médio; a rede privada recruta principalmente professores diplomados no ensino superior; e mais de dois terços dos professores de Santa Catarina têm menos de 15 anos de trabalho; os que atuam nas redes estadual e privada estão há mais tempo no magis-

13 Segundo Valle (200I), os professores brasileiros encontram-se numa situação similar à de seus colegas dos países subdesenvolvidos em termos de idade, notadamente dos países vizinhos da América Latina; trata-se de um corpo docente situado numa faixa de idade bastante jovem: pouco mais de $60 \%$ dos professores argentinos do primário e do secundário tinham menos de 40 anos em 1994; eles eram quase 70\% na Venezuela. Nas regiões em desenvolvimento, os professores são geralmente mais jovens que seus colegas das regiões desenvolvidas: 60\% dos professores do primário e do secundário na França tinham mais de 40 anos em 1994; seus colegas da Alemanha com mais de 40 anos ultrapassavam os $70 \%$. 
tério que seus colegas da rede municipal' ${ }^{14}$. Tais fatores, na maioria dos casos, contrariam a eficiência, de modo que grande parte das vantagens que favorecem as crianças dos meios mais privilegiados não se explica pela lógica meritocrática, mas pelas características de sua escolarização.

Nessa perspectiva, consideramos que, seguindo a lógica descentralizadora, a educação nacional não pode ser vista como uma via de mão única, mas sobretudo como uma sucessão de encruzilhadas que supõe caminhos radicalmente diferentes. Cada um deles contém bifurcações que implicam escolhas pessoais, geralmente circunscritas a condições sociais predeterminadas. Alguns percursos estão destinados aos meios mais desfavorecidos, nos quais as condições materiais, o status, as condições de trabalho e o engajamento dos professores, assim como os resultados escolares dos alunos, não cessam de se degradar; outros estão abertos àqueles que podem participar da competição escolar, em que as estratégias familiares e o comprometimento dos agentes da instituição concorrem para o sucesso escolar.

\section{Uma lógica descentralizadora: a adesão forçada dos municípios}

Diante da natureza das políticas de democratização, procuraremos orientar esta análise sobre a municipalização do ensino a partir de três abordagens, que embora pareçam distintas são interdependentes: a primeira coloca em evidência o processo decisório típico das organizações burocráticas e remete ao caráter centralizador do sistema de educação nacional; a segunda, pautada no valor genérico do termo descentralização, combina diferentes sentidos etimológicos; a terceira refere-se aos processos de racionalização, incorporados pelo discurso oficial e justificados pelas lutas em favor da democratização.

Com base na reflexão teórica de Crozier (1981), selecionamos alguns elementos que definem a funcionalidade das organizações burocráticas: I . o poder de decidir tende a situar-se nas posições que podem assegurar a estabilidade geral do sistema e a concretização dos seus objetivos funcionais; 2. o poder de adotar decisões para interpretar e aplicar as regras, bem como substituí-las, tende a afastar-se cada vez mais das células de execução ou dos níveis hierárquicos para os quais elas foram criadas; 3. o dever de preservar o equilíbrio entre os diferentes segmentos do sistema, pela adaptação das normas elaboradas na cúpula, tende a considerar

I4 Valle (200 I) constata também que o tempo médio de exercício dos professores da educação básica brasileira não ultrapassa os dez anos, variando ligeiramente em razão da rede de ensino. 
principalmente os interesses dos níveis superiores em detrimento das particularidades e necessidades dos níveis inferiores.

A segunda abordagem compreende um conjunto de expressões que identificam uma estrutura descentralizada, a saber: o federalismo (designa uma multiplicidade de órgãos não centrais que estabelecem diretrizes e normas a serem prescritas para as diferentes partes da coletividade); o regionalismo (indica a divisão histórica e geográfica do território ou do estado); a autonomia (define a atribuição de uma parte da autoridade à gestão administrativa local ou territorial, a entidades ou setores profissionais); a organização administrativa (consiste na transferência de competências às autoridades regionais, a seus delegados ou representantes municipais).

Enfim, visando racionalizar as organizações burocráticas, esses princípios e procedimentos explicitados na abordagem anterior orientaram a constituição do sistema educacional brasileiro ${ }^{15}$, o qual se apresenta estruturado em redes (ou subsistemas) públicas e privadas e em níveis de ensino (educação infantil, ensino fundamental, médio e superior). Essas redes podem atuar em todos os níveis, mas as instituições públicas se submetem a algumas prioridades estabelecidas no âmbito legal. Acreditando-se autônomas, as redes são administradas ou inspecionadas por esferas hierárquicas, que constituem um poder triangular: federal, estadual e municipal, fator que as torna subordinadas umas às outras.

A descentralização do sistema educacional brasileiro aparece como uma necessidade na Lei de Diretrizes e Bases da Educação Nacional (Lei n. 4.024/6I ) ${ }^{16}$ e é identificada como uma estratégia de modernização do país e de suas instituições. Ela está, neste caso, relacionada a aspectos como a extensão territorial do país e a diversidade cultural, ao regime federativo e democrático, mas, sobretudo, ao financiamento do ensino. Para Newton Sucupira ${ }^{17}$, a descentralização funcional e territorial do sistema de educação constitui uma das grandes conquistas dessa LDB. Concebida por esse conselheiro como descentralização articulada, ela previa a extensão do espaço político da escola, considerado como fundamental à ampliação de sua iniciativa, criatividade e participação na direção do processo educacional.

15 Sobre a burocratização da educação em Santa Catarina, ver Valle (1996).

16 É importante ressaltar que as discussões sobre a descentralização do ensino brasileiro estiveram sempre presentes na legislação educacional, como mostra Oliveira (1999, p. | I-36), tendo aparecido pela primeira vez no Ato Adicional de 1834, que "constitui um marco na descentralização, ampliando os poderes provinciais em detrimento do central...".

17 Membro do Conselho Federal de Educação. 
Esse novo dispositivo legal preconizava também - ao menos em princípio - a autonomia das diferentes esferas administrativas, por um intercâmbio entre elas, que transcendia a condição de subordinação hierárquico-funcional e assegurava a especificidade das diversas redes de ensino (Valle, 1996). Nestes termos, essa lei não somente respaldava formalmente a constituição dos sistemas municipais de educação mas os incentivava.

Antes mesmo de ter sido operacionalizada, a proposta descentralizadora da primeira LDB/I96I assume novas características em virtude do Golpe Militar de 1964. Em exposição apresentada na $4^{\text {a }}$ Reunião Conjunta dos Conselhos de Educação (em 1967), Orlando Ferreira de Mello, Osvaldo Ferreira de Mello e Francisco Brasinha Dias ${ }^{18}$, na qualidade de porta-vozes do novo regime instituído, se consagram a ressignificar os princípios norteadores dessa lei e a redefinir seus contornos, com base na Doutrina de Segurança Nacional e Desenvolvimento. Para esses conselheiros, no "federalismo contemporâneo" (modelo difundido pelo regime autoritário) a autonomia, entendida como poder de auto-organização e auto-administração, tem como limite os aspectos relativos à segurança, à preservação da unidade nacional e ao processo de desenvolvimento do país. No que concerne à descentralização preconizada por essa lei de educação, os conselheiros entendem que a competência dos estados para organizar e administrar seus próprios sistemas de ensino não pode ser outorgada sem restrições: ela está condicionada a um conjunto de princípios e normas, determinados pelas necessidades de segurança e integridade da nação (Valle, 1996, p.42-43).

O regime ditatorial introduz, portanto, uma nova ordem (des)centralizadora, ancorada num complexo sistema de regulação em nível federal e estadual ${ }^{19}$. Temendo a perda de poder pelo alto (pressão de organismos internacionais), mas sobretudo pela base (autonomia de estados e municípios), o Estado autoritário foi reticente à descentralização. As conseqüências dessa ordem conduzida pelo Ministério da Educação, ao longo das décadas de 60 e 70 (século XX), com o apoio da

18 Membros do Conselho de Educação do Estado de Santa Catarina.

19 Segundo Schmidt (2000, p.44), "a descentralização tem sido utilizada [...] como estratégia de desestruturação de setores econômicos e de setores de serviços de caráter estatal. No setor da educação, foram sendo incrementados com este objetivo na América Latina e Caribe, fomentados pela ONU, Unesco, Banco Mundial, cujos enfoques, apesar de apresentarem algumas diferenças, contêm um substrato comum no sentido de se alterarem as relações entre o Estado e os cidadãos". 
maioria das instâncias administrativas estaduais ${ }^{20}$, podem ser claramente observadas em Santa Catarina ${ }^{21}$, onde a descentralização das decisões ficou relegada ao plano do discurso e a constituição dos sistemas municipais de ensino não foi suficientemente sustentada. Nesse período, que caracterizamos como a primeira "onda" da massificação do ensino fundamental (especialmente nas séries iniciais), observase nitidamente a presença da rede estadual tanto na expansão do número de unidades escolares quanto no crescimento da matrícula.

Os movimentos de caráter contestatório e reivindicatório, que eclodem desde 1980 no Brasil, são portadores de críticas contundentes a respeito do centralismo, do autoritarismo e da ineficiência do aparelho de Estado, perante as necessidades de universalização do ensino obrigatório. Esses movimentos se confrontam, no entanto, com as medidas propostas pelo modelo neoliberal, as quais parecem se conformar ao princípio enunciado por Daniel Bell (apud Boltanski, Chiapelo, 1999), referindo-se a "um Estado muito grande para administrar as pequenas coisas e muito pequeno para gerenciar as grandes coisas".

Clamando por reformas políticas, econômicas, sociais e administrativas em todos os níveis, esses movimentos anunciam o fim do Regime Militar, caracterizado, segundo Schmidt, por

...um grande consenso em torno da descentralização, por se entender que ela era um instrumento necessário à democratização política. Entram nesse consenso de gestão dos assuntos do Estado tanto aqueles que, com base nos velhos preceitos liberais, defendem a proteção dos interesses individuais contra a intervenção do Estado, quanto forças de esquerda, que, baseadas em ideais libertários, pretendem superar os limites da democracia representativa. (2000, p.54)

Visando atender as novas expectativas de democratização e superar a justaposição de reformas e de recomendações emanadas das altas esferas de poder, o governo da Nova República (instaurado em 1985) se propõe a descentralizar os sistemas de ensino, limitando assim os inconvenientes do gigantismo burocrático

20 Sobre os limites e perspectivas da democratização da educação em Santa Catarina após 1962, ver Valle (2000, p. I I I- 124).

21 O processo de municipalização do ensino fundamental pode ser observado igualmente em outros estados da federação. Segundo Rosar e Sousa (1999, p. I | 8), "a concretização dessa política no Estado do Maranhão tem produzido mais efeitos publicitários do que melhorias significativas na qualidade dos serviços educacionais oferecidos à população". 
(nos termos descritos por Boltanski e Chiapello, 1999), os quais só podem ser enfrentados em escala local. Dois dispositivos legais estabelecem as prerrogativas essenciais da nova lógica descentralizadora que se tenta impor: a Constituição Federal de 1988 e a nova Lei de Diretrizes e Bases da Educação Nacional (Lei n. 9.394/96). Eles enfatizam a necessidade de repartição das responsabilidades em termos de educação entre as três esferas de poder (federal, estadual e municipal). Com a descentralização, numerosas competências são transferidas para as regiões e as coletividades municipais, que ampliam sua competência jurídica em matéria de escolarização de crianças, jovens e adultos, e multiplicam assim as instâncias e níveis de decisão. Mas o compromisso com a manutenção do ensino fundamental recai principalmente sobre as redes municipais, cujo nível de engajamento nas políticas educacionais permanecia muito baixo 22 .

Na tentativa de ilustrar certas particularidades locais (culturais, políticas, educacionais), alguns governadores e prefeitos implementam mecanismos inovadores de gestão, que visam motivar os agentes envolvidos no processo educacional e organizar a competência dos setores que estão sob sua responsabilidade. Nessa perspectiva, a descentralização deve operar não mais por tarefas sucessivas - geralmente fragmentadas - mas por blocos de competências, elaborados conjuntamente e garantidos pela transferência de meios financeiros e de recursos humanos.

Segundo Schmidt (2000, p.84-88), as ações da Secretaria Estadual de Santa Catarina voltaram-se desde 1980 para o co-gerenciamento e a transferência de atribuições do Estado para os municípios. Essa posição descentralizadora foi explicitada primeiramente no Plano Estadual de Educação (1980-1983), do Governo Jorge Bornhausen, reforçada em seguida no processo de planejamento participativo efetuado no Governo Amin ( 1982 - 1986): os municípios passaram a atender sobretudo as demandas por educação infantil23. O Governo Pedro Ivo-Cacildo Maldaner ( 1987 1991) mostrou-se também muito receptivo ao projeto descentralizador, tendo deslo-

22 Em 13 de setembro de 1996, foi aprovada a Emenda Constitucional n. 14, que institui o Fundo de Manutenção e Desenvolvimento do Ensino Fundamental e de Valorização do Magistério - Fundef -, o qual seria regulamentado pela nova Lei de Diretrizes e Bases da Educação Nacional - LDBEN (Lei n. 9.394/96). Esse dispositivo visa efetivar a transferência das responsabilidades em matéria de ensino fundamental para os municípios.

23 Segundo Arelaro (1999, p.6I-89), o Estado de São Paulo difere-se dos outros estados da federação por haver universalizado completamente $\mathrm{o}$ atendimento pré-escolar, assegurando às crianças de 6 anos de idade uma "preparação para a alfabetização", implementada sob a responsabilidade das redes municipais de ensino. 
cado progressivamente para os municípios parte das responsabilidades concernentes às séries iniciais do ensino fundamental. Mas seria o Governo Kleinübing ( | 99 | - | 994) que iria estabelecer as diretrizes claras de municipalização do ensino fundamental, amplamente incorporadas no programa de governo de Paulo Afonso ( 1995- 1998).

Antes de refletir sobre as implicações de uma lógica municipalista, analisaremos a divisão das responsabilidades no que concerne ao ensino fundamental em Santa Catarina, lembrando, com Oliveira (1999, p.33), que esta "indução à municipalização não considera a questão dos recursos humanos em condições de gerir, com sucesso, um sistema de ensino". Para tanto, procuraremos abordar dois aspectos principais: a evolução do número de unidades escolares e da matrícula inicial por rede de ensino, no período compreendido entre 1980 e $2002^{24}$, a partir de dados secundários recolhidos junto a organismos oficiais ${ }^{25}$. Esta expansão do ensino fundamental foi caracterizada como a segunda "onda" da massificação, destacandose a situação das séries iniciais, cuja municipalização efetivamente foi iniciada e em relação às quais, portanto, esse movimento aparece mais claramente.

\section{Responsabilidade em matéria de ensino fundamental}

Analisando a distribuição do número de unidades escolares por rede de ensino, no período compreendido entre 1980 e 2000, verificamos que a participação da rede federal em matéria de escolarização obrigatória é insignificante (permanecendo em torno de $0,04 \%$ ao longo do período). A rede particular mantém-se estável até 1990 (2,5\%) chegando a 6,7\% em 2000. A manutenção do ensino fundamental fica mesmo sob a responsabilidade das redes estadual e municipal: enquanto o estado, responsável em 1980 por 57\% do número de escolas, reduz significativamente sua presença no ensino obrigatório (apenas 25\% em 2000), os municípios aparecem como os principais mantenedores desse nível de ensino, ampliando de $41 \%$ em 1980 o número de unidades escolares para quase $70 \%$ em 2000. Este movimento caracteriza de fato a municipalização do ensino em Santa Catarina, fenômeno que ocorreu pela transferência de um importante número de escolas estaduais para os municípios.

24 A periodicidade foi definida conforme as fontes disponíveis, diferenciando-se em razão dos dados levantados.

25 Tendo em vista que os dados levantados junto a diferentes fontes nem sempre são coincidentes, procuraremos desenvolver uma análise cuidadosa deles. 
Responsabilidades em matéria de ensino de $1^{a}$ a $4^{a}$ série

Analisando a distribuição do número de unidades escolares do ensino de $1^{a}$ a $4^{a}$ série, por rede, no período compreendido entre 1996 e 2002, observa-se que a rede federal é praticamente ausente. A rede particular, responsável por 3,6\% do número de escolas em 1996, sofre um aumento importante, passando para 7,3\% em 2002. A primeira etapa da escolarização obrigatória é, essencialmente, sustentada pelas redes estadual e municipal: enquanto o estado mantinha 52\% do número de escolas em 1996, diminuindo para 24,5\% em 2002, os municípios empreendem uma expansão extraordinária, passando de 44\% em 1996 para 68\% em 2002. Esta expansão aconteceu principalmente no ano de 1997, quando os municípios quase dobraram suas redes, mostrando claramente a descentralização forçada dos sistemas escolares em Santa Catarina, principalmente das séries iniciais.

\section{Matrícula inicial do ensino fundamental}

Analisando a evolução da matrícula inicial do ensino fundamental ${ }^{26}$ por rede de ensino durante uma década (1992-2002), verificamos (Gráf. 2) que a presença da rede federal é insignificante (menos de $0,2 \%$ ao longo do período). A rede particular mantém-se estável: em torno de 8\% da matrícula. Esse nível de ensino está sobretudo sob a responsabilidade da rede estadual e das redes municipais (mais de 92\%). As mudanças em termos de escolarização ocorrem entre essas duas redes, particularmente no biênio 96-98 quando a matrícula das redes municipais cresce e o número de crianças freqüentando a rede estadual diminui consideravelmente. $\bigcirc$ Estado era responsável por 67\% da matrícula em 1992, contra $24 \%$ das redes municipais. Em 2002, os municípios atendem $42 \%$ dos inscritos, enquanto a matrícula das escolas estaduais cai para menos de $50 \%$.

Matrícula inicial de $1^{a}$ a $4^{a}$ série

O movimento de escolarização pode ser observado principalmente no ensino de $1^{a}$ a $4^{a}$ série. Analisando a distribuição da matrícula inicial por rede, no período compreendido entre 1996 e 2002 (Gráf. 3), constata-se que a rede federal mantém-se ausente. A rede particular continua estabilizada (em torno de 7\%). A matrícula oscila entre a rede estadual e as redes municipais, a exemplo do que

26 Sobre as tendências da matrícula no ensino fundamental regular no Brasil, ver Mansano Filho et al. (1999, p.37-60). 
GRÁFICO 2

MATRÍCULA INICIAL DO ENSINO FUNDAMENTAL, POR REDE DE VINCULAÇÃO - SANTA CATARINA, 1992-2002

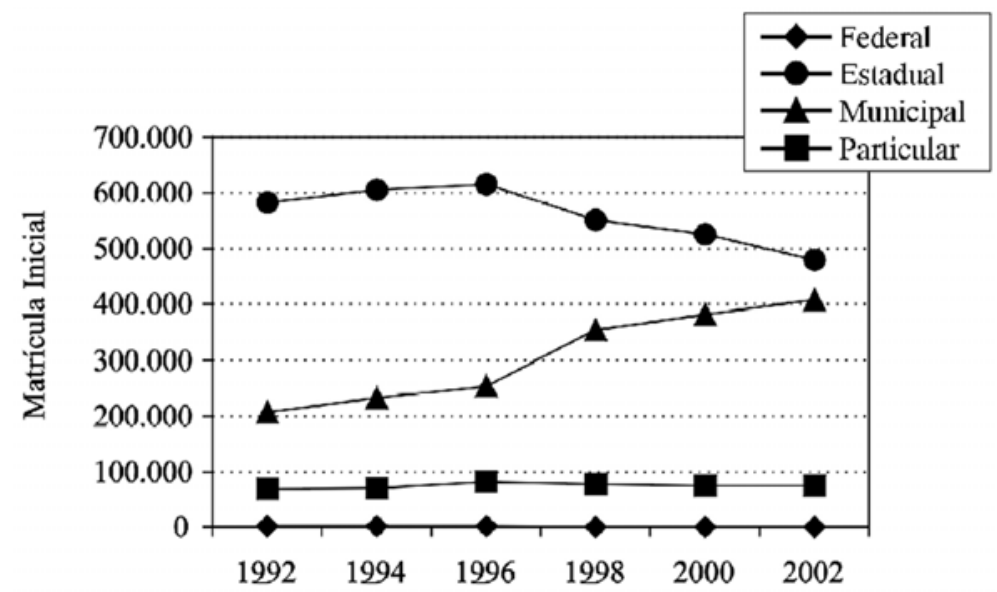

Fonte: SED/Dirp/Censo Escolar (1992-2002).

\section{GRÁFICO 3}

MATRÍCULA INICIAL DE $\left.\right|^{\text {a }}$ A $4^{\text {a }}$ SÉRIE, POR REDE

DE VINCULAÇÃO - SANTA CATARINA, 1996-2002

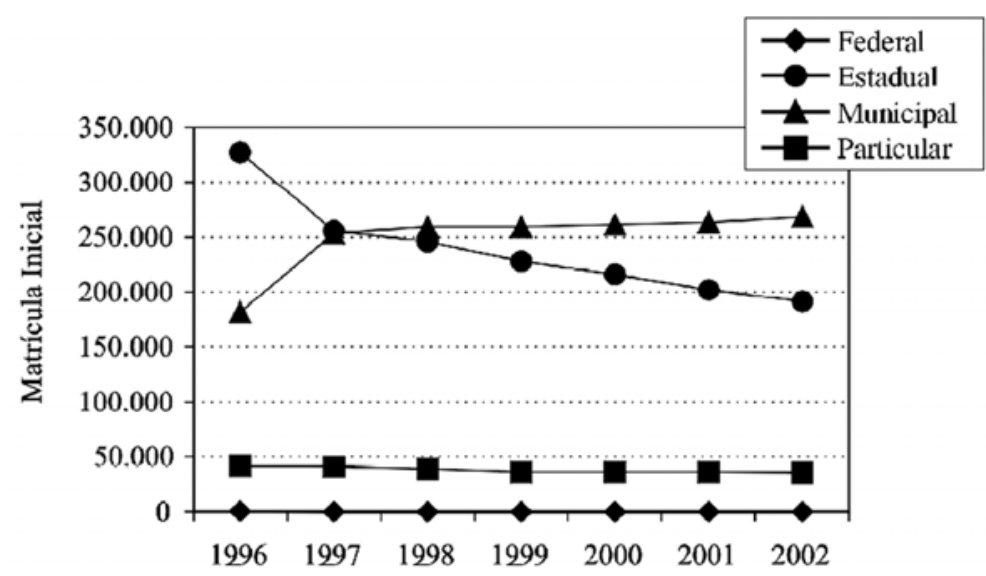

Fonte: SED/Dirp/Censo Escolar ( $1996-2002)$. 
ocorreu com a expansão da rede física e da matrícula no ensino fundamental. Mas é nas séries iniciais que a mudança - ou a transferência de responsabilidades aparece mais claramente. $\bigcirc$ ano de 1997 pode ser caracterizado como marco do movimento de municipalização do ensino: 59\% das crianças matriculadas nas séries iniciais freqüentavam uma escola estadual em 1996, contra 33\% nas redes municipais; a matrícula da rede estadual cai para 46\% em 1997, mesmo percentual de alunos das redes municipais (que elevam sua matrícula para 46\%). Esse movimento evoluiu progressivamente nos anos seguintes: cai para 39\% o número de alunos freqüentando a rede estadual e elevam-se para $54 \%$ os matriculados nas redes municipais em 2002, registrando-se um crescimento de $48 \%$.

\section{Uma lógica municipalista: as armadilhas da descentralização}

Reestruturados, descentralizados, com menos hierarquia, com procedimentos mais simplificados, os sistemas municipais de ensino conferem maior autonomia às escolas, que, confrontadas entre si, são impelidas a investir mais na eficiência e na qualidade das suas ações educacionais. Nesse sentido, parece óbvio que a descentralização responsabilize mais os agentes e facilite seu engajamento no funcionamento das redes de ensino, favorecendo as mudanças e inovações desejadas. Além disso, as coletividades locais têm tendência a se envolver com maior intensidade nos projetos educativos, promovidos no âmbito da municipalidade. Todas essas mudanças parecem seguir na direção de um Estado ao mesmo tempo menos centralizado, mais eficaz e adaptável às necessidades da população. Os municípios podem oferecer a oportunidade a cada escola de formar verdadeiras comunidades de aprendizagem, centradas sobre a cooperação e a interdependência no lugar da competição e do individualismo.

Se, de um lado, não se pode esquecer que a educação nacional preenche um papel fundamental na democratização da sociedade brasileira e que a descentralização é necessária em virtude das características históricas e geográficas de nosso país, por outro lado não se pode deixar de mencionar as conseqüências negativas das propostas descentralizadoras sobre o sistema de educação nacional, em termos de exclusão da escola e na escola. A lógica descentralizadora não se tem mostrado eficaz na eliminação das desigualdades escolares, atestadas por numerosos estudos desenvolvidos no campo educacional. Sob o abrigo da descentralização, não se oferecem as garantias indispensáveis à igualdade de acesso a uma educação básica de qualidade. 
Embora não se possa afirmar que exista uma ligação direta - e automática entre municipalização e persistência das desigualdades, a descentralização é portadora de novas formas de diferenciação. Longe de contribuir para a consolidação de uma democracia de proximidade, ela pode acabar instituindo, na esfera local, uma nova estrutura burocrática, que faculta o estabelecimento de relações pessoais e políticas com os detentores do poder municipal, tão distante da comunidade escolar quanto se encontra a burocracia estadual ou federal.

Constituindo-se num dispositivo complexo em que, em tese, ninguém detém o poder mas todos detêm uma parcela dele, a descentralização possibilita uma opacidade dos mecanismos de decisão, sem evitar contudo os excessos da burocracia. A repartição confusa dos papéis acaba diluindo as responsabilidades e gerando uma sobreposição de funções, que coloca as redes municipais numa posição inferiorizada na estrutura hierárquica do sistema de educação nacional.

A estrutura descentralizada pode também provocar diferenças importantes entre pequenos, médios e grandes municípios, dependendo dos recursos financeiros disponíveis ou do grau de mobilização em favor da escolarização. Geralmente, o orçamento contempla distintamente os interesses educacionais, o que significa que os recursos não são programados nem aplicados de maneira idêntica: num município, os custos com transporte e merenda escolar, assim como manutenção das escolas, infra-estrutura esportiva, capacitação de pessoal são imputados à rubrica da educação; noutro, essas despesas podem compor outras rubricas orçamentárias.

Além disso, um pequeno município situado na zona rural (com mil habitantes por exemplo) não poderá conceber os mesmos projetos educacionais que seu vizinho situado na capital ou com 300 mil habitantes ou mais. As mudanças em favor de um ensino de qualidade acabam sendo implementadas apenas pelas redes de ensino mais bem situadas geográfica e economicamente, enquanto a pequena escola municipal de zona rural ou de periferia pena para integrar as inovações e melhorar o nível de habilitação de seu corpo docente.

Se considerarmos ainda que os recursos financeiros permanecem centralizados nos níveis estadual e federal - é nos gabinetes dos ministros em Brasília e dos secretários de Estado que continuam sendo tomadas todas as decisões educacionais -, verificamos que a lógica descentralizadora transforma os municípios em vítimas dessa faceta da democratização. A autonomia preconizada é do tipo: "vire-se por si mesmo", em se tratando das condições de trabalho, mas submeta-se às orientações e prerrogativas superiores em nome da unidade nacional. As redes municipais são colocadas numa posição meramente reivindicatória em relação às instâncias 
superiores. A qualidade dos serviços educacionais e as condições de funcionamento ficam totalmente atreladas às escolhas políticas efetuadas em cada município ou às iniciativas isoladas de prefeitos e secretários, reproduzindo profundas disparidades escolares.

Os municípios são portanto os que mais sofrem os efeitos perversos da lógica descentralizadora, que acaba transformando-se numa porta aberta para a reprodução das injustiças em termos de educação. Em conseqüência disso, as redes municipais são reservadas às classes menos favorecidas (os dominados, no sentido dado por Bourdieu, 1998). Quanto mais descentralizado o sistema de ensino mais a escola parece estar aparelhada para selecionar os mais fortes: as portas da universidade permanecem fechadas às camadas populares: "merecedoras", certamente, mas "malnascidas".

\section{REFERÊNCIAS BIBLIOGRÁFICAS}

AMADO, G. Educação média e fundamental. Rio de Janeiro: José Olympio; Brasília: INL, 1973. ARELARO, L. R. G. A Municipalização do ensino no Estado de São Paulo: antecedentes históricos e tendências. In: OLIVEIRA, C. et al. A Municipalização do ensino no Brasil: algumas leituras. Belo Horizonte: Autêntica, 1999. p.61-89.

ARROYO, M. G. A Formação, direito dos profissionais da educação escolar. Política de capacitação dos profissionais da educação, Belo Horizonte: FAE/RHVP, 1989. p.35-71 .

BOBBIO N. Estado, governo e sociedade: para uma teoria geral da política. 3 ed. São Paulo: Paz e Terra, 1990.

BOLTANSKI, L.; CHIAPELO, È. Le Nouvel esprit du capitalisme. Paris: Gallimard, 1999.

BOURDIEU, P. La Distinction. Paris: Minuit, 1979. . La Domination masculine. Paris: Seuil, 1998.

BOURDIEU, P.; PASSERON, J.-C. Les Héritiers: les étudiants et la culture. Paris: Minuit, 1964. BRASIL. Leis, decretos etc. Constituição da República Federativa do Brasil, de 8 de outubro de 1988. Emenda Constitucional n. 14, de 13 de setembro de 1996.

Lei n.4.024, de 20 de dezembro de 1961. Lei de Diretrizes e Bases da Educação Nacional. 
Democratizar, descentralizar, municipalizar

Lei n. 5.692, de II de agosto de 1971. Fixa diretrizes e bases para o ensino de $1^{\circ}$ e $2^{\circ}$ graus.

Lei n. 9.394, de 20 de dezembro de 1996. Lei de Diretrizes e Bases da Educação Nacional.

BRASIL. Ministério da Educação. Censo escolar de 200 I. Brasília: 2003.

. Reunião Conjunta dos Conselhos de Educação: quinze anos de intercâmbio e colaboração. Brasilia: MEC/CFE/CEEs, 1980.

CASTEL, R. Le marginaux dans l'histoire. In: DONZELOT, J. L'Exclusion: l'état des savoirs. Paris: La Découverte, 1996. p.32-4I.

CROZIER, M. O Fenômeno burocrático: ensaios sobre as tendências burocráticas dos sistemas de organização modernos e suas relações, na França, com o sistema social e cultural. Brasília: Editora Universidade de Brasília, 1981.

CRUZ, M. L. T. C. Dicionário de ciências sociais. Rio de Janeiro: FGV, 1987. p.469-47I .

CURY, C. R. J. 500 anos de educação no Brasil. Belo Horizonte: Autêntica, 2000. p.567-584. A Educação como desafio na ordem jurídica.

DUBAR, C. La Crise des identités: l'interprétation d'une mutation. Paris: PUF, 2000.

La Socialisation: construction des identités sociales et professionnelles. 2 ed., Paris: Armand Colin, 1998.

DUBAR, C.; TRIPIER, P. Sociologie des professions. Paris: Armand Colin, 1998.

DUBET, F. L'Exclusion scolaire: quelles solutions? In: PAUGAM, S. L'Exclusion: l'état des savoirs. Paris: La Découverte, 1996. p.497-518.

FERRARO, A. R. Diagnóstico da escolarização no Brasil. Revista de Educação, São Paulo, n. 12 , p.22-47, set.-nov. 1999.

LANGOUËT, G. A Escola francesa se democratiza, mas a inserção social torna-se cada vez mais difícil. Perspectiva, Florianópolis, UFSC, v.20, n. esp. p.85- 106, jul./dez. 2002.

LEFORT, C. A Invenção democrática: os limites do totalitarismo. São Paulo: Brasiliense, 1983.

MACPHERSON, C. B. A Democracia liberal: origens e evolução. Rio de Janeiro: Zahar Editores, 1978.

MANSANO FILHO, R. et al. Tendências da matrícula no ensino fundamental regular no Brasil. In: OLIVEIRA, C. et al. A Municipalização do ensino no Brasil: algumas leituras. Belo Horizonte: Autêntica, 1999. p.37-89. 
OLIVEIRA, C. A Municipalização do ensino brasileiro. In: OLIVEIRA, C. et al. A Municipalização do ensino no Brasil: algumas leituras. Belo Horizonte: Autêntica, 1999. p. I I-36.

ROSAR, M. F. F.; SOUSA, M. S. A Política de municipalização no Estado de Maranhão: alguns aspectos contraditórios. In: OLIVEIRA, C. et al. A Municipalização do ensino no Brasil: algumas leituras. Belo Horizonte: Autêntica, 1999. p.91-121.

SANTA CATARINA. Secretaria de Estado da Educação e do Desporto. Censo escolar. Florianópolis, I991-2001, 1996-2002 e 1992-2002.

Matrícula inicial. Florianópolis, 1989-1999 e 1980-2000.

Plano Estadual de Educação 1969/1980. Florianópolis, 1969.

SCHMIDT, W. A Municipalização do ensino fundamental em dois pequenos municípios rurais de Santa Catarina: Anitápolis e Santa Rosa de Lima (1987 a 1995). São Paulo, 2000. Tese (dout.) Pontifícia Universidade Católica.

VALLE, I. R. Burocratização da democratização: um estudo sobre o Conselho Estadual de Educação do Estado de Santa Catarina. Florianópolis: UFSC, 1996.

Da "Identidade vocacional" à "identidade profissional": a constituição de um corpo docente unificado. Perspectiva: Sociologia e Educação: Revista do Centro de Ciências da Educação, v. 20, n. esp. p.209-230, jul.-dez. 2002.

Le Jeu bureaucratique fait-il obstacle aux enjeux démocratiques? Le cas du Conseil d'Éducation de l'État de Santa Catarina au Brésil, depuis 1962. Histoire et sociétés de I'Amérique Latine. Paris: L'Harmattan, n. 12, p. I I I-124, 2000.

Professionnalisation et formation des enseignants: la socialisation professionnelle des enseignants de la la à la 4ª année à Santa Catarina - Brésil. Paris, 200 I . Tese (dout.) Paris $\mathrm{V}$.

VALLE, I. R.; MIZUKI, G. E. P.; CASTRO, I. M. F. Socialização profissional do corpo administrativo: profissionalização dos secretários municipais de educação do Estado de Santa Catarina, 2003. [Relatório de Pesquisa]

ZAGO, N. Processos de escolarização nos meios populares: as condições da obrigatoriedade escolar. In: NOGUEIRA, M. A. (org.) Família e escola: trajetórias de escolarização em camadas médias e populares. Petrópolis: Vozes, 2000. p. 17-41.

ZANTEN, A.V. Fabrication et effets de la ségrégation scolaire. In: PAUGAM, S. L'Exclusion l'état des savoirs. Paris: La Découverte, 1996. p.281-29I.

Recebido em: agosto 2003

Aprovado para publicação em: agosto 2003 